\title{
The Role of Spousal Separation on Norms Related to Gender and Sexuality among Himba Pastoralists
}

\author{
Brooke Scelza $^{1, *(\mathbb{D})}$, Sean Prall ${ }^{2}$ ad and Kathrine Starkweather ${ }^{3}(\mathbb{D}$ \\ 1 Department of Anthropology, University of California Los Angeles, Los Angeles, CA 90095, USA \\ 2 Department of Anthropology, University of Missouri, Columbia, MO 65211, USA; sprall@missouri.edu \\ 3 Department of Anthropology, University of Illinois, Chicago, IL 60607, USA; kstark20@uic.edu \\ * Correspondence: bscelza@gmail.com
}

Citation: Scelza, Brooke, Sean Prall, and Kathrine Starkweather. 2021. The Role of Spousal Separation on Norms Related to Gender and Sexuality among Himba Pastoralists. Social Sciences 10: 174. https://doi.org/ 10.3390/socsci10050174

Academic Editors: Paula Sheppard and Kristin Snopkowski

Received: 31 March 2021

Accepted: 14 May 2021

Published: 17 May 2021

Publisher's Note: MDPI stays neutral with regard to jurisdictional claims in published maps and institutional affiliations.

Copyright: (c) 2021 by the authors. Licensee MDPI, Basel, Switzerland. This article is an open access article distributed under the terms and conditions of the Creative Commons Attribution (CC BY) license (https:/ / creativecommons.org/licenses/by/ $4.0 /)$.

\begin{abstract}
The gender-specific labor demands of arid pastoralism often lead to spousal separation. Men typically respond in one of two ways: engage in mate guarding tactics, or loosen restrictions on female sexuality. Among Himba pastoralists in northwest Namibia, the latter strategy is dominant. Rooted in a history of matriliny, Himba have strong norms promoting female sexual autonomy. We propose that these conditions, combined with a stochastic resource base, have led to women utilizing a combination of formal and informal partnerships to meet their needs and the needs of their children. Aspects of Himba socioecology also increase the costs of mate guarding for men and lower the costs of extra-pair paternity, further bolstering a concurrency strategy. Using a mix of quantitative and qualitative data, we show how spousal separation, female autonomy, and concurrency are linked, and suggest that in this harsh environment having a mix of formal and informal romantic partners may be less costly and more beneficial than a system of monogamous marriage.
\end{abstract}

Keywords: spousal separation; female autonomy; multiple mating

\section{Introduction}

The sexual division of labor has long been viewed as a core element of human social organization (Durkheim 1933; Becker 1985; Murdock and Provost 1973). Husbands and wives form complementary partnerships, taking on different tasks linked to production and reproduction, driven by the common goal of efficiently raising joint offspring (Gurven et al. 2009). At times, this kind of labor specialization requires that spouses spend significant periods of time apart, for example on multi-day foraging trips, while moving livestock between camps, or when engaging with long-distance trade networks. When this happens, it raises a conundrum for men: the very duties of fatherhood that drive him to leave are those that put his future paternity at risk. In order to balance these competing demands for production and reproduction, social norms are often put in place that restrict women's autonomy and monitor their behavior. These restrictions are widely viewed as efforts to prevent paternity loss while spouses are apart. However, the relationship between spousal separation and female autonomy is not always so clear. There are instances where instead of restricting women's autonomy, sexual freedom is tolerated, or even encouraged. This alleviates the costs of mate guarding for men and their families, but increases the chance that they will invest in children who are not biologically their own. This second situation is less common, but may be adaptive in some circumstances. To explore this possibility, we provide a case study of one population of Himba pastoralists living in northwest Namibia. In this community spousal separation is common, extra-pair paternity is frequent, and the majority of men and women have concurrent marital and nonmarital partnerships. By looking at concurrency within its larger social context, we gain a greater understanding of why these less conventional marital norms may arise and thrive in certain settings. 


\subsection{Spousal Separation in Socioecological Context}

A common response to the dilemma of spousal separation is the enactment of various social norms that inhibit women's autonomy. Placing restrictions on women's behavior and movements constrains their ability to engage in extramarital relationships and reduces the risk of paternity loss. The manifestations of these restrictions vary across cultures, from monitoring women's movements (Dickemann 1979) and their menstrual cycles (Strassmann 1992); to claustration and veiling (Pazhoohi et al. 2016); to extreme physical disfigurement such as foot-binding, infibulation, and other forms of genital mutilation (Mackie 1996); to intimate partner violence (Stieglitz et al. 2018). But evolutionary scholars have long contended that the underlying motivation for all of these practices is the same: to prevent women from engaging in nonmarital sex, and thus prevent a misallocation of paternal investment (Wilson and Daly 1995; Smuts 1995; Buss 2002).

Nomadic pastoralists are prime examples of this relationship, as they are particularly prone to frequent spousal separation and often enact limits on women's autonomy (Randall 1995). Pastoralism typically occurs in marginal environments, with marked seasonality and limited periods of adequate rainfall. In these cases, herders must move their animals to fodder, rather than bringing fodder to the animals. Migration allows herders to maximize access to pastureland, either by shifting the entire herd seasonally, or by splitting the herd across camps when forage is limited (Dyson-Hudson and Dyson-Hudson 1980). Although mobility strategies vary across groups, typically men are more mobile than women, both in undertaking major shifts in locale, as well as in their daily movements. They are also more likely to spend nighttime hours outside of camp, protecting the herd. In a cross-cultural study, Becker (2019) sought to examine the relationship between pastoralism and female sexual autonomy, predicting that individuals from pastoralist groups will be more likely to practice social norms that inhibit female mobility and sexuality than those with more sedentary modes of production. Using a multinational dataset, she found that women from traditionally pastoralist ethnic groups were more likely to have undergone infibulation and have more restricted mobility, were more tolerant of intimate partner violence, and adhered to more restrictive norms about their sexual behavior. The paper goes on to show that it is male absenteeism in particular, rather than patriarchal structures, that led to the high frequency of these behaviors.

Despite this overall trend, not all nomadic pastoralists fit the pattern that Becker illuminates. Data from the Standard Cross-Cultural Sample show that almost half of pastoralist cultures are reported to have moderate to high levels of female infidelity (Scelza 2013). Most famously, Nuer pastoralists traditionally maintained several forms of marriage, recognizing the distinction between pater and genitor, and allowing for women, both formally and informally, to have multiple partners (Evans-Pritchard 1951; Gough 1971). Even in cultures that fit the correlation Becker finds, the picture is complex. Among Maasai, who practice female circumcision and have strong patriarchal norms, extramarital partnerships are common. As one ethnographer writes, “ ... lover relationships are an all- pervasive part of IlOitai society. I knew of no Maasai woman in the Ilkerin area who had not had at least one lover during her married life which shows that the practice is basic to IlOitai social existence" (Knowles 1993, pp. 198-99). Spousal separation is key to the enactment of these relationships, "Because husbands can be away for weeks at a time, and everybody knows who is where, there is little chance of the lovers being caught" (Knowles 1993, p. 199).

\subsection{The Costs and Benefits of Concurrency}

There is no clear consensus about why spousal separation leads to strict norms for sexual behavior in some places and more relaxed norms in others. A behavioral ecology perspective would suggest that we might find clues by comparing the costs and benefits of different strategies for both men and women. For men, there are two main types of costs: the costs involved in keeping one's current partner faithful (mate guarding), and the costs of lost paternity, when children born to their wives are fathered by someone else. The costs to women reflect similar trade-offs. If she attempts a non-marital partnership, 
there is a risk of harm to her or her children. If she remains faithful, she might miss out on important resources or opportunities that could better her situation. These costs must then be compared with the benefits of staying versus straying for men and women, and those benefits can be material, social, or genetic (Scelza 2013; Walker et al. 2010).

First, let us consider weighing the costs of mate guarding with the costs of lost paternity. One way this has been clearly exemplified is through studies of inheritance systems. Where inheritance is patrilineal, the costs of (mis)investment in non-biological kin are greater. When men can acquire transferable wealth, they are incentivized to pass it to their close kin, sons being the most frequent recipients. However, this only makes sense when those sons are likely to be his. In this case, expending energy on restricting female sexuality in order to ensure paternity may be well worth the cost compared to the potential loss of passing one's wealth on to a non-biological relative. It is likely for this reason that we find frequent associations between patriliny and restricted female autonomy (Barry 2007; Hendrix and Pearson 1995). This is also believed to be one reason why matriliny and pastoralism rarely co-occur. As groups in sub-Saharan Africa shifted their mode of production from horticulture to pastoralism (i.e., heritable wealth increased), they also typically shifted from matrilineal to patrilineal social structures (Holden and Mace 2003). The increased fitness returns associated with male biased inheritance are implicated in the shift to pastoralism, likely driving mate guarding behaviors and other practices to avoid lost paternity.

Patrilineal inheritance often co-occurs with virilocal residence, where married couples co-reside with the husband's kin. This can lower the costs of mate guarding at the same time that costs of lost paternity rise, because having kin available allows men to offset the time and energy involved in tracking their partners' whereabouts onto other interested parties. On the contrary, where matrilineal inheritance and uxorilocal residence coincide, women remain with their own kin after marriage, which makes mate guarding more difficult for men. The additional freedom (sexual and otherwise) that women have in these cases is less problematic given that paternity is irrelevant to the inheritance of property in this system.

Other sociodemographic factors can also affect the relative costs of mate guarding and lost paternity. For example, in some ecologies, child labor is a critical component of household production. Where children play important roles in labor or childcare, they are subsidizing part of their investment, which can mitigate the cost of lost paternity. Another contributing factor is the adult sex ratio (ASR), which affects the likelihood of finding partners (Schacht et al. 2017). Where women are in the majority, men can more easily absorb the costs of lost paternity because they are more able to find new or additional partners. Female-biased ASRs are generally associated with greater instability in partnerships and lower paternal investment (Guttentag and Secord 1983; Schacht and Mulder 2015). Conversely, when males are in the majority, mate guarding becomes more cost effective, because the chances of recuperating paternity loss, or finding another partner, are lower.

For women, concurrency is associated with other costs, which must also be considered. Engaging in non-marital partnerships can bring on physical, emotional, or economic harm. Betzig (1989) finds that infidelity, and specifically female infidelity, is a leading cause of divorce cross-culturally. In cultures where women's access to resources is intimately tied to their marital status, this can mean severe economic loss, in addition to social and reputational harm. Intimate partner violence (IPV) is also commonly linked to infidelity (Goetz et al. 2008; Daly et al. 1982). The risks of IPV and the potential losses associated with divorce vary by social system, just as they do for men. Women living in matrilineal, matrilocal societies tend to have a greater ability to divorce, and face fewer costs when they do (Takyi and Gyimah 2007). Maintaining matrilineal kin ties can also reduce the risk of spousal violence (Sedziafa and Tenkorang 2016). The risks of IPV and divorce, at whatever level, must be weighed against other risks associated with monogamy. For example, in ecologies where resources are stochastic, relying on a single man as your domestic partner 
may be more risky than having several men to draw resources from. Similarly, being monogamously married means that if her husband dies, a woman and her children could face a period of scarcity. The risks are compounded if there is a female-biased ASR, as the chances of remarriage are lower.

In addition to weighing different types of costs, we must also consider any benefits that can accrue from concurrent partnerships. For men, their own concurrency is likely to have a direct, linear effect on their fitness-more partners typically leads to more children. Among both the Ache and the Tsimane, higher-status men have more extramarital partnerships (Hill and Hurtado 1996; Von Rueden et al. 2011). Men can also benefit from women's concurrency, through social exchange, kin selection, or intrasexual competition. For women, the relationship between number of partners and number of children is less straightforward. Concurrency can bring social or material benefits that can positively impact her fitness (Scelza 2013; Hrdy 2000; Starkweather and Hames 2012). For example, Ache women with multiple spouses have more surviving children than those with only one spouse, likely due to the importance of men's resource provisioning (Hill and Hurtado 1996). However, the literature on direct correlations between number of partners and number of children is mixed (Borgerhoff Mulder and Ross 2019; Jokela et al. 2010).

Several ethnographic accounts exemplify how concurrency can benefit both men and women. Among Massai, it is allowed, and in fact encouraged, for men of the same age-set to share sexual partners, including their wives. The practice is believed to help cement the bond between men. Talle writes, "The intimacy between males in the Maasai society is forcefully expressed through the sharing of girlfriends when they are morans, and wives when they are married elders ... In some cases a husband may urge his wife to be impregnated by a certain age-mate of his, whom he admires either for his oratory skills, bravery, or certain physical qualities. The child strengthens the relationship between the two men ... " (Talle 1994, p. 283). The importance of these male alliances is believed to be critical to resilience in the marginal environment Maasai live in (Mwangi and Ostrom 2009). Women are also reported to benefit from these relationships. Knowles (Knowles 1993, p. 201) writes of women's lovers, "They can provide an informal network of people who may be called upon to help in a crisis." This can be particularly critical for women who are more resource insecure: " ... women whose husbands are poor in cattle may have to rely upon links with lovers in order to be able to feed their children ... . A good lover is therefore not only a sexual partner but also someone who looks after their lovers' needs," (Knowles 1993, p. 200). Furthermore, similar to men, Maasai women forged relationships with their husband's lovers, becoming friends and relying on each other to exchange small items (Knowles 1993; Llewellyn-Davies 1978).

Among previous generations of Inuit, partner sharing was common, and as with the Maasai, the relationship of concurrency with social alliances and resources has been identified as causal. In this case, the links were between couples, who could rely on each other in times of crisis, and in the exchange of goods and services when needed. Wife exchange due to spousal separation was believed to be as much about having a subsistence partner as a sexual one (Guemple 1986). The relationship therefore was not just about sharing of spouses as sexual partners, but as domestic and productive partners.

Material benefits and social support have been linked to the practice of partible paternity, common to lowland south Amerindian populations. Under this practice, intercourse with multiple men is necessary to "build" the offspring, and as a result children can have primary, secondary, and even tertiary fathers. Numerous hypotheses regarding the benefits of this practice for men and women have been explored (Walker et al. 2010). Women may benefit by adding additional sources of support during pregnancy and after birth. In the Bari, a forager-horticulturalist population of Venezuela, women benefit by receiving additional resources from multiple investors, resulting in an increased likelihood of carrying pregnancies to term, and higher infant survival (Beckerman and Valentine 2002). Conversely, men may benefit through increased reproductive opportunities, particularly 
high-status men, or by solidifying alliances with friends and kin, similar to the Maasai practice described above.

\subsection{Study Overview}

In almost all of these examples, we see that reproductive decisions reflect local historical and ecological pressures. Human behavioral ecologists frame this in terms of conditional strategies (Cronk 1991). This approach can help us to understand why a particular pressure can lead to different outcomes in different settings. In this paper we examine how one particular pressure, spousal separation, can lead to relaxed norms about female sexuality, in stark contrast to the typically described pattern where spousal separation is associated with intensive mate guarding and restrictions on women's behavior prevails. To do this, we focus on the costs and benefits of three interrelated behaviors: mate guarding, female autonomy, and concurrent partnerships in a case study of Himba pastoralists, living in rural, northwest Namibia. We take a multimodal approach, relying on a combination of qualitative and quantitative data collected during a 10-year study of formal and informal relationships in one Himba community. We begin with a detailed ethnographic explanation of our three key factors. Following this, we present quantitative data from a series of experimental and naturalistic data. Finally, we bring these results together with historical and other qualitative data to make the case that high female autonomy, sexual freedom and concurrent partnerships are likely an adaptive response to spousal separation in this context.

\section{Study Setting}

The Himba are semi-nomadic pastoralists living in the northwest Kunene region of Namibia. Currently there are about 50,000 Ovahimba living in Namibia and Angola, though exact numbers are difficult to detect due to their high mobility. Our research has concentrated on a single community located about halfway between the regional capital of Opuwo and the border town of Epupa, where we have been working since 2010. At any given point the community has about 40 active households and about 1000 residents. General information about Himba culture, norms, and practices has been published elsewhere (Bollig 2006; Malan 1995).

\subsection{Himba Demography and Family Life}

Himba households consist of men, their wives, children, and additional extended kin, ranging from 8-25 members. Polygyny is common, and first marriages are arranged, ideally to first cousins. First marriages for women often occur in early childhood, but a change of residence does not occur until sometime after puberty, and many of these marriages are never consummated. Men marry for the first time in their late 20s, creating a large age gap between a man and his first wife. Subsequent wives tend to be closer in age, and are more likely to be "love matches." Divorce is frequent, and subsequent marital partners are often self-selected. There is a clear sexual division of labor present, with men engaging in livestock-related tasks, including taking cows to sources of water and out to pasture. Women primarily engage in domestic labor, including gathering firewood, cooking, and collecting water from distant waterpoints, as well as growing, harvesting, and processing corn and other domesticates from household gardens.

From an early age, children assist in various gender-specific domestic tasks, and child labor is vital to the household economy. Girls as young as five assist in childcare and cooking, and when older, assist with water and firewood collection, and help their female kin in the household gardens. Boys' primary responsibility is to herd goats, although girls may participate in this activity as well. As a result, girls are generally viewed as more valuable and useful in the domestic pursuits of the household. Fosterage is common, with $38 \%$ of women fostering out at least one child (Scelza and Silk 2014).

Girls' high labor value may partially explain the low adult sex ratio (ASR) found in this population, estimated as 0.71 (approximately 71 men for every 100 women) in one 
sample (Scelza et al. 2020c). Despite differences in household labor between boys and girls, Himba do not report any overt cultural norms that suggest a gender bias in parental care or investment. The drivers of this sex bias have not been systematically studied, but Himba anecdotally report higher child and infant mortality in boys, which may contribute to a low ASR. In sub-Saharan Africa, the high domestic value of girls, combined with potential economic value delivered through bride price, is thought to explain sex differences in childhood nutrition and mortality (Wamani et al. 2007; Svedberg 1990).

\subsection{Spousal Separation}

As is true in many pastoralist societies, there is a constant fluidity in Himba people's movements. Seasonal shifts are common, with most households keeping a main residence (ozonganda), as well as additional livestock posts (ozohambo). Elder male heads of household, unmarried men and women, and some children are most likely to shift to cattle posts. Polygynously married men might take one of their wives with them to the cattle post and leave the other behind; wives might also head to one of the small stock posts with their children, while their husbands stay with the larger stock. These movements affect the likelihood that both formal and informal partners will be in close proximity at different points in the year.

In addition to spousal separation that results from the duties of pastoral production, short- and long-term visits to kin also impact the likelihood that husbands and wives will be co-resident at any given time. In particular, because post-marital residence is patrilocal, women often return to their natal compounds, and most of the time they do this alone or with young children, but without their husbands. Previously, we found that 50\% of married women in this area were co-residing with natal kin at the time of our census (Scelza 2011b). These visits often center on reproductive events. Women typically return to their mother's compound (or another close maternal relative) during the last trimester of pregnancy, and stay through the birth and for several months afterward. The length of their postpartum stay varies depending on whether they have a co-wife at home (allowing for a longer absence), the birth order of the child, and whether they had a difficult birth or recovery. However, in addition to these factors, lengthy peripartum visits can also indicate troubles in the marriage. We have heard multiple stories of women going home for a birth, and then choosing to stay, or their husbands never coming back to "pick them up," resulting in eventual divorce.

Shorter-term trips for ceremonies, funerals, and political meetings also occur frequently for both men and women. Women often travel without their husbands, either to visit kin in neighboring compounds, or for particular ceremonies or trips to town (Scelza 2011b). Previously, we showed that for a sample of 40 nights where men reported where they slept, on $24(60 \%)$ they were sleeping away from home (Prall et al. 2018). These trips can be taken with or without one's spouse, but we have heard repeatedly from interlocutors that ceremonies and funerals open up opportunities to meet with informal partners.

Finally, there are everyday separations that should be considered. As is common in subsistence-based societies, the division of labor typically means that men and women take on different tasks, spending large parts of the day apart. For men, who are herding, this can extend into the night, as they look for rogue cattle, or travel at night or early in the morning to avoid the heat of the day. Although these separations are short, they do open up opportunities for visiting informal partners. One interlocutor reported to us that there is an informal rule that a man should not return home after dark if he is kept away late, as arriving at night could cause him to find his wife with her lover. 


\subsection{Female Autonomy}

Himba are one of the few populations in the world that practice double descent, where individuals maintain membership in both a matriclan and a patriclan. In their specific case, the majority of wealth is passed matrilaterally between brothers and from mother's brother to sister's son, but there is patrilineal inheritance of residential property, as well as rights related to ritual practices (Gibson 1956).

Matriliny often co-occurs with greater autonomy and sexual freedom for women, but it is much more common in horticultural societies than among pastoralists and agriculturalists (Barry 2007; Hendrix and Pearson 1995). The combination of matrilateral inheritance and pastoralism among Himba is very unusual. Historically, shifts from horticulture to pastoralism are thought to accompany shifts from matriliny to patriliny (Holden and Mace 2003). It is possible that Himba are in a state of disequilibrium, and will eventually also transition to a patrilineal inheritance system, but this has yet to occur. For now, the link between high female autonomy and matrilateral inheritance remains, although there is some evidence that men are shifting their preferences toward patrilineal inheritance (Scelza et al. 2019).

Currently, women have significant freedoms associated with reproductive decisionmaking. Although arranged marriages are common for first marriages, love matches, where the couple choose each other and then go to their families to formalize the arrangement, constitute the majority of second marriages. Women are also able to divorce with ease, and do so frequently. Births outside of marriage are not generally stigmatized and there are norms in place to name a "social father" for that child. An extensive fosterage system also provides a degree of support for women, as they often leave children born out of wedlock or from a previous union with their mothers when they remarry (Scelza and Silk 2014).

\subsection{Concurrent Partnerships}

In addition to the freedoms that Himba women have to divorce easily and (at least for second marriages) choose their spouses, it is also common and normative for both men and women to have non-marital partners (Scelza and Prall 2018; Hazel 2012). The widespread acceptance of this practice has led to the highest rate of extra-pair paternity ever recorded, with $48 \%$ of children fathered by someone other than the husband (Scelza et al. 2020b). A combination of genetic evidence and paternity assertions acquired through interviews also showed that both men and women are attuned to paternity, and both very accurately detect nonpaternity. However, this high rate of extra-pair paternity does not always lead to the titration of investment that evolutionary scholars would predict. Both experimental and observational evidence has shown that Himba men place great value on their role as social fathers, even when they suspect they are not the biological father (Prall and Scelza 2020b; Scelza et al. 2020a). There is some evidence that spreading paternity across multiple partners positively impacts women's reproductive success, as women who have more children with lovers have overall greater fertility (Scelza 2011a).

There is also circumstantial evidence that informal partners are an important source of support for women when strategizing to provide for their children. In a study of partner preferences, women reported valuing resource-related traits in both formal and informal partners (Scelza and Prall 2018). In a study of partner preferences, we previously showed that women who had high resource needs were open to a greater number of potential partners (Prall and Scelza 2020a). This, combined with ethnographic evidence where women speak about the gifts that their lovers bring them, indicates that we should be paying more attention to the role of informal partners within broader networks of support.

\section{Methods}

\subsection{Ethical Approval}

This work was approved by the UCLA Institutional Review Board (\#10-000238). Community support was granted by the Chief of Omuhonga, Basekama Ngombe. All participants provided oral consent. 


\subsection{Ethnographic Data}

Informal, unstructured interviews and participant observation have been ongoing since 2010 when the project began. The reproductive history interviews described below often included follow-up conversations in response to structured survey questions, in order to gain context about people's reproductive decisions. Focus groups have also been held on topics including partner preferences, marriage decisions, polygyny, matriliny and inheritance, parental care and biases in investment, and nonmarital partnerships. All the quoted statements included in this paper occurred during either the reproductive history or female autonomy interviews described below, or during formal focus groups.

\subsection{Structured Interviews}

Semi-overlapping sets of interview questions were used with men and women in order to include data on the three main aspects of this study: spousal separation, female autonomy, and concurrency. These data were collected as part of a broader project on marital and family dynamics among Himba, and so were not constructed specifically for the purposes of this study. Each set of questions is described below, along with information on associated samples (see Table S1 for more details).

1. Spousal Separation: A set of 44 women were asked about the locations of each of their romantic partners over the previous 12 months. Their responses were given seasonally in four blocks: early dry (July-Aug), dry (Sep-Dec), early wet (Jan-Mar), and wet (Apr-Jun).

2. Female Autonomy: Three sets of questions on female autonomy were asked of both men and women. The first set asked about women's freedom of movement $(\mathrm{N}=76)$. Four binary questions asked whether it was permitted for a woman to travel alone to the following places: her natal compound, a funeral, the clinic, and the regional capital of Opuwo. Next, an open-ended question asked how long a wife could visit her natal compound without her husband getting upset $(\mathrm{N}=84)$. Finally, a group of men and women $(N=67)$ were asked about whether IPV was acceptable under different conditions, including having a non-marital partner. Additional details on these surveys are shown in the Supplementary Materials.

3. Tolerance of Infidelity: Himba men $(\mathrm{N}=51)$ were presented with a vignette on female sexual autonomy. The vignette stated that a married Himba woman had a boyfriend who she sees regularly and has sex with. They were first asked a binary question of whether or not this was acceptable (i.e., socially normative). They were then asked what would happen if a woman did this. These responses were coded into categories (e.g., physical harm, reputational harm, multiple responses per man allowed) while maintaining the full text of responses for further context. Finally, the men were asked if they had ever seen or heard about this happening, and to describe what happened in an open-ended response.

4. Relationship Histories: Men $(\mathrm{N}=42)$ and women $(\mathrm{N}=81)$ were asked a set of questions about each of their current partners, including the length of the relationship and the last time they had sex (for information on a total of 303 relationships). Another set of men $(\mathrm{N}=42)$ and women $(\mathrm{N}=108)$, some overlapping with the previous sample, were asked about the most recent gift they had either received from (women) or given to (men) each of their current romantic partners. This resulted in data on 338 partnerships. When possible, we recorded details about the transfer such as the amount of cash, type of livestock, and type of food item.

5. Food Insecurity: Food insecurity was measured among women $(\mathrm{N}=118)$ using a modified form of the cross-culturally validated household hunger scale (Deitchler et al. 2010). The survey asks five questions with a three-point response scale. Total scores can range from 0 to 10, with higher scores denoting greater food insecurity. Next, we measured diet breadth using a seven-day recall where women were asked if they had access to the following common foods over the last week: maize, sour milk, meat, melon, sugar, and other store-bought foods. 


\subsection{Analysis}

Descriptive statistics are presented on the various aspects of female autonomy. For the binary questions on female mobility, responses were added together to form a summary score. Descriptive statistics were also presented on the female concurrency vignette and the relationship history and resource transfer data.

To analyze the resource transfer data, days since last gift $(\mathrm{N}=319)$ was estimated using a Gaussian regression model of log +1 transformed days, with varying intercept by participant $(\mathrm{N}=144)$, and age and partner type as predictors. Gift type was estimated using a categorical model, with age and partner type as predictors. Because some women reported multiple partners, varying intercepts by individual participants were also included.

To predict the effects of boyfriend age and marital status on time since last sex (log transformed $+1, \mathrm{~N}=150$ ) with informal partners, a Gaussian regression was used, with age and marital status also employed to predict the variance on the outcome. Varying intercepts by individual participants were included to correct for multiple relationships by individual respondents.

To estimate the effects of concurrency on food insecurity a truncated Poisson regression was used to predict food insecurity score by age and relationship category. Because so few women were unmarried without a boyfriend, we constructed a categorical variable relationship category, dividing women between married with a boyfriend $(\mathrm{N}=52)$, married without a boyfriend $(\mathrm{N}=10)$, and unmarried with a boyfriend $(\mathrm{N}=56)$. Women who provided both food security and concurrency data in multiple years were included for each year they were interviewed. In total, 158 responses were recorded. To correct for multiple responses per participant, a varying intercepts parameter was included.

All models were fit to RStan (Stan Development Team 2019) using the brms (Bürkner 2017) package in $R$, using three chains of 5000 iterations each, and convergence assessed using $\hat{r}$ scores. All models used regularizing priors. For some analyses, age was missing for several participants, so age was imputed using the $m i()$ function. Posterior mean and $95 \%$ credible intervals (CI) of coefficients are reported below, and additional model results shown in the Supplementary Materials.

\section{Results}

\subsection{Spousal Separation}

Husbands and wives were found to be co-resident for $65 \%$ of the year, and women were in the same general location as their boyfriends for $78 \%$ of the year (Figure 1). Propinquity with boyfriends was more steady across the seasons, whereas spousal separation was most prominent in the start of the dry season, with co-residence during that period occurring less than half the time. Another way to measure spousal separation is by looking at the time since last sexual contact, as reported by both men and women. Himba men report that when they are in the same location as their wives, they have sex regularly (daily, or every couple of days if they have multiple wives) and our data seem to support that. The modal response in our dataset was sex within the last 24 hours $(\mathrm{N}=70)$. However, we see a non-linear pattern after that (Figure 2 and Figure S1). The second most commonly reported answer was that the couple had sex "last month." In total, $26 \%$ of individuals reported it had been at least 30 days since having sex with their spouse. This does not include another $14 \%$ who reported that they (or their wife) were pregnant or had recently given birth and so were practicing a period of peripartum abstinence, which in some cases lasted more than a year. 


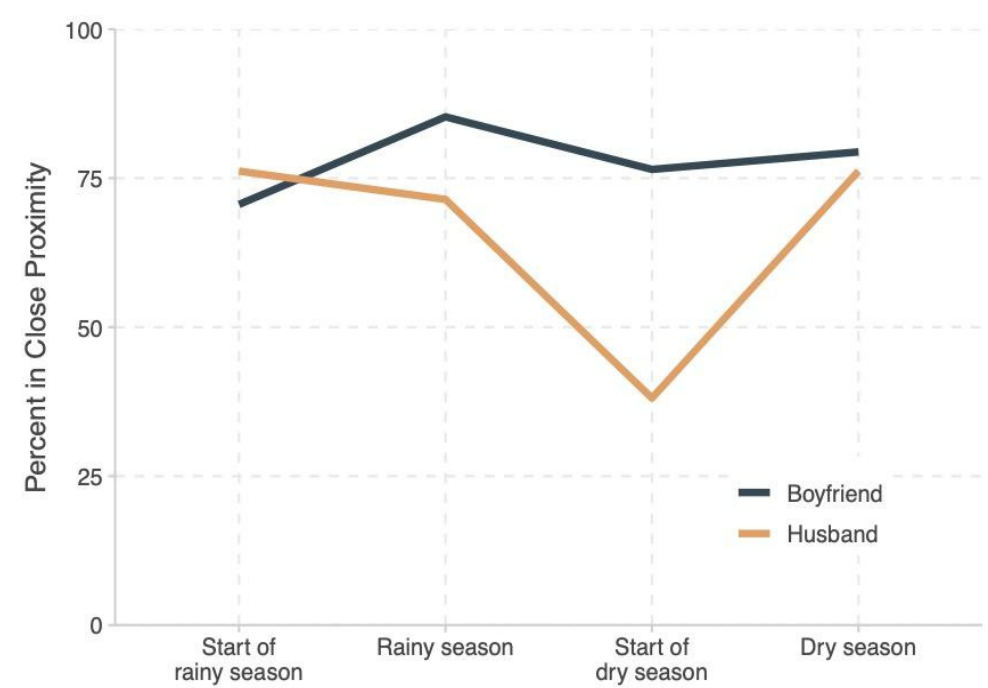

Figure 1. Co-residence by season. Women $(\mathrm{N}=42)$ reported whether they were residing near husbands and boyfriends at four points over the previous year.

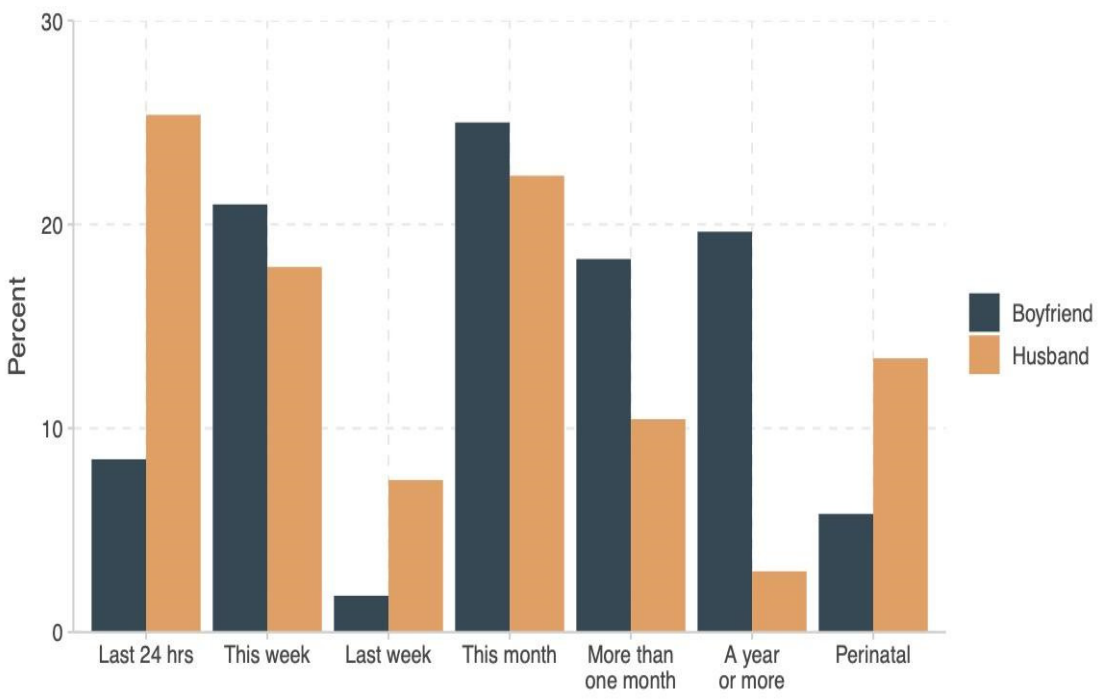

Figure 2. Time since last sexual contact with husband and boyfriend.

\subsection{Female Mobility and Reproductive Freedom}

When asked about their preferences, Himba had variable opinions about whether husbands should accompany wives when they travel (Figure 3A). Although the majority of both men and women reported it was acceptable for a married woman to take trips for functional purposes on her own (e.g., to the clinic or to town), they were more split on whether she should be accompanied for more social visits. Although $62.5 \%$ of women thought it was acceptable for a woman to go to a funeral or ceremony on her own, almost the same percentage of men thought it was not acceptable. Their opinions about visits to a woman's natal compound were also strikingly different, with $87.5 \%$ of women saying it was acceptable for her to visit her kin on her own, compared to only $50 \%$ of men. When asked about the appropriate length of a wife's visit to her natal compound, the median length of time was 30 days. Women and men differed in the length of time, where women reported a median time of 30 days, whereas men reported it was only appropriate to visit for a median of 14 days (Figure 3B). 

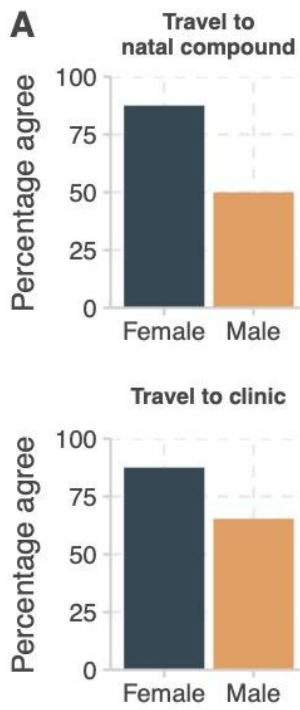
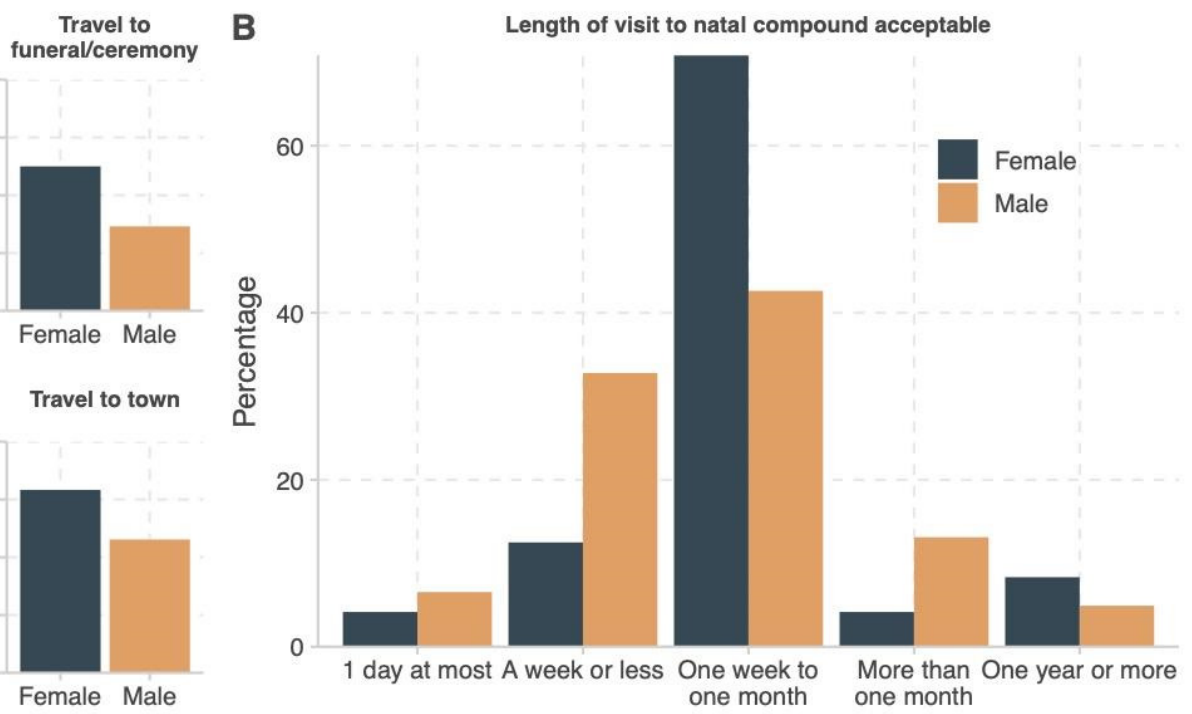

Figure 3. Views on freedom of movement. (A) Men's and women's responses to a binary question of whether it is acceptable to travel alone to a variety of places. (B) The acceptable length of time men and women feel a wife can visit her natal compound for a routine (non-pregnancy related) visit.

Men and women were also asked about the circumstances under which they deemed intimate partner violence to be acceptable. Across circumstances, women were more likely than men to report that a husband hitting his wife was acceptable (Figure 4). The only case where a majority of men said it was acceptable to hit a woman was if she neglected their children, and even here it was a slim majority (52\%). Older respondents tended to find intimate partner violence in response to the queries less acceptable, although the effects of age tended to be highly uncertain, with credible intervals overlapping zero (Table S2). One exception was to the question on refusal of sex, where older participants rated IPV in response to wives' refusal to have sex as appropriate (standardized age: $\beta=0.73, \mathrm{CI}=0.13-1.39$ ).

In our vignette study, Himba men were split on whether it was acceptable for a woman to have a boyfriend with whom she has regular contact (Figure 5). Older men were more likely to find this acceptable than younger men (standardized age: $\beta=0.69, \mathrm{CI}=0.10-1.31$, Table S3), but overall a majority felt this was unacceptable. Despite this, an overwhelming majority $(98 \%)$ reported that they were aware of this practice. When asked what would happen if such a relationship occurred, views were split across several types of punishment (Figure 5C), including physical harm (to either the wife or her boyfriend) and harm to the marital relationship, with $23.2 \%$ reporting that there would be no punishment at all.

\subsection{Concurrency and Resource Transfers}

Combining both women's and men's reporting of informal romantic partners highlights some important demographic patterns. Of 227 instances where a boyfriend's age and marital status are known, married boyfriends are 48.2 years old on average $(\mathrm{sd}=14.7)$ compared to unmarried boyfriends at 31.6 years on average $(\mathrm{sd}=11.7)$. Modeling of sexual recall data indicates that younger men are more likely to have had recent sex with girlfriends (standardized age $\beta=0.90, \mathrm{CI}=0.21-1.59$ ), but marital status alone has no impact on time since last sex (married $\beta=-0.31, \mathrm{CI}=-1.16-0.51$ ). However, interactions between boyfriend marital status and boyfriend age indicates that younger unmarried men are more likely to have had sex more recently, but that older married men show a shorter duration since last sex with girlfriends than do older unmarried boyfriends ( $\beta=-1.15$, $\mathrm{CI}=-2.00--0.31$, Table S4). These results should be interpreted with caution, given the age differences between married and unmarried boyfriend means there are few instances of unmarried older men present in the data (Figure S2). 


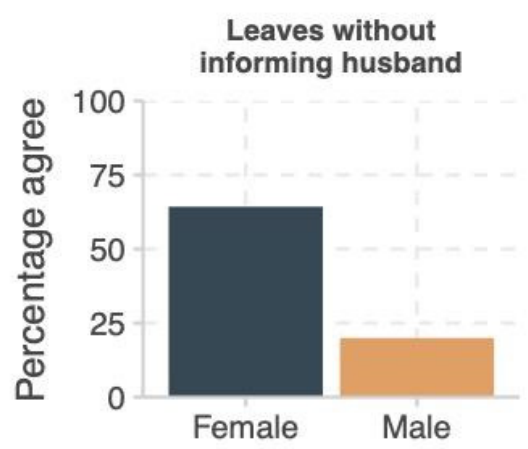

Refuses sex

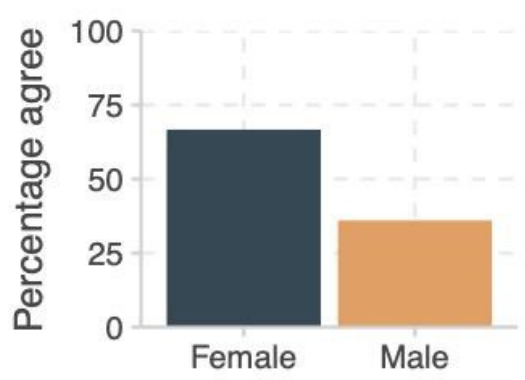

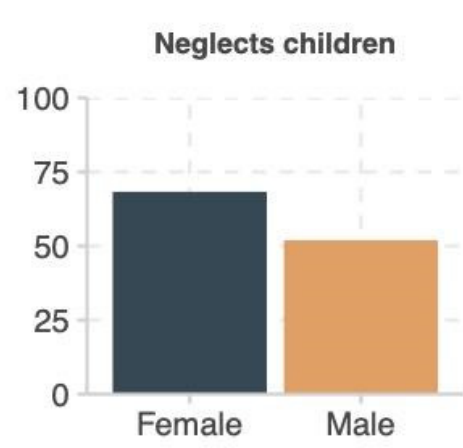

Burns food

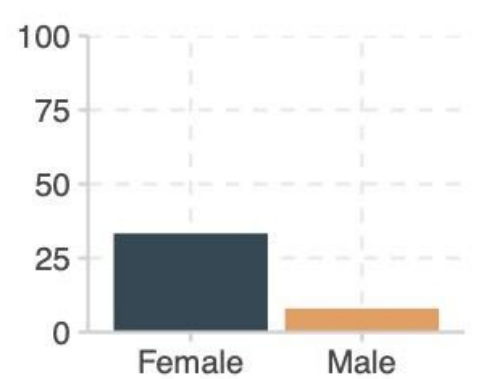

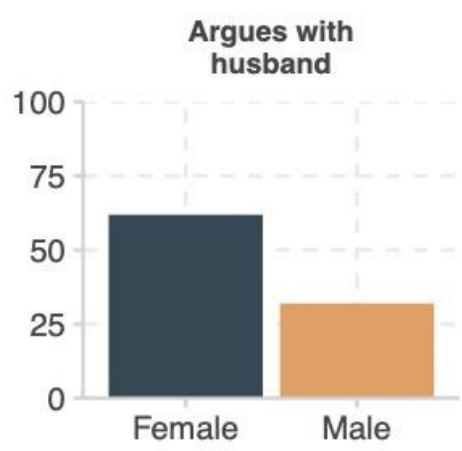

Has sex with boyfriend

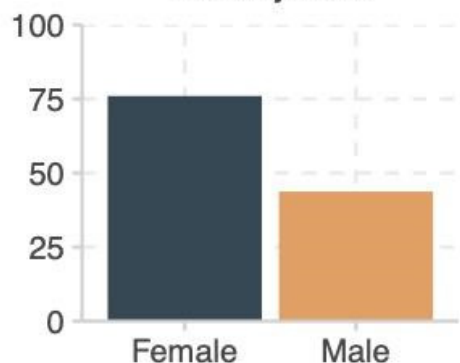

Figure 4. Views on reasons for intimate partner violence. Men and women were asked whether it was acceptable for a husband to hit his wife for any of the following reasons.

A

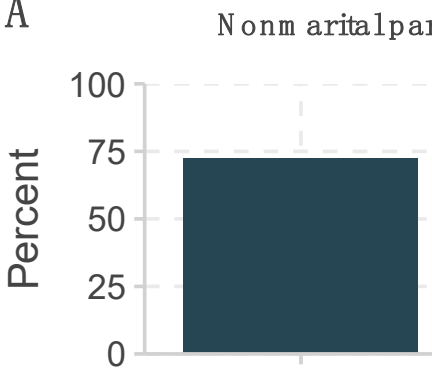

No
Yes

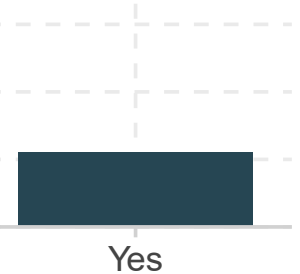

B

Nonm aritalpartnersh ip s happen frequen tly?

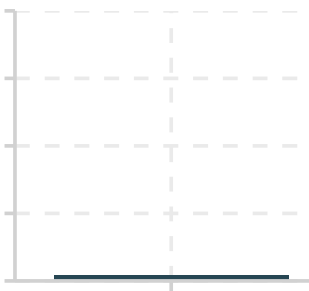

No

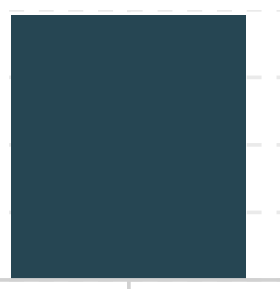

Yes

C Pun ishm en t for nonm aritalpartnersh ip

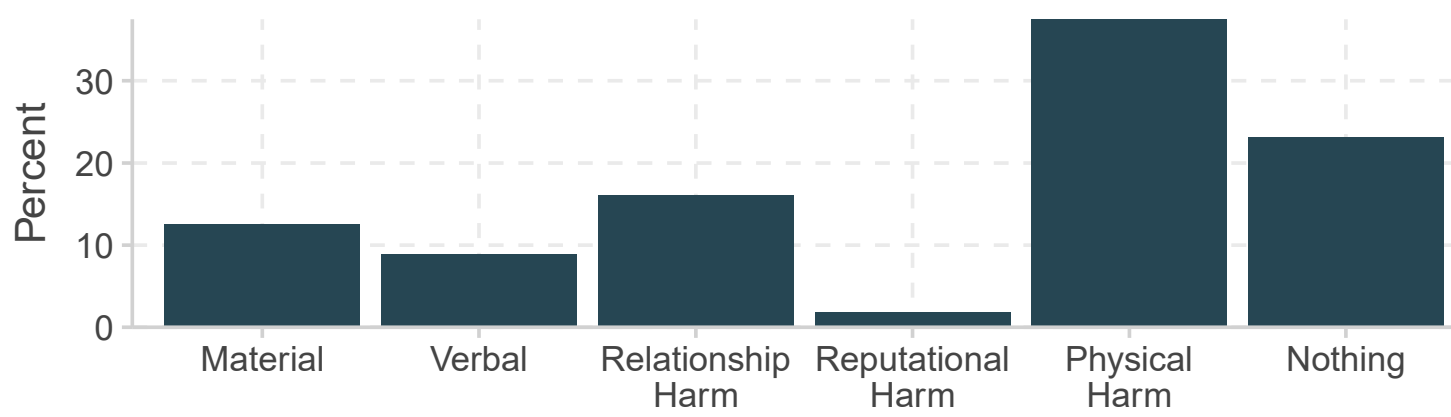

Figure 5. Views on concurrency. Men were asked (A) whether it was OK for a married woman to have a regular sexual relationship with a boyfriend, (B) whether they had heard of this happening, and (C) to list the potential repercussions for this act.

Women reported the date and type of their most recent gift from each romantic partner. On average, women received gifts from their husbands more recently than from their boyfriends (Figure 6), and this difference was supported by model results (effect of husband on log days: $\beta=-1.47, \mathrm{CI}=-1.87--1.06$, Table S5). Cash was the most common type of gift from both husbands and boyfriends, though it accounted for a greater 
proportion of gifts from boyfriends. Husbands were more likely to provide food and livestock whereas boyfriends were more likely than husbands to gift token items such as bracelets and beads (Figure 7, effect of husband on log-odds of gift: bracelets/beads $\beta=-1.92, \mathrm{CI}=3.25--0.69$; food $\beta=0.73, \mathrm{CI}=0.40--0.05$; livestock $\beta=1.63, \mathrm{CI}=0.37-2.85$, Table S6).

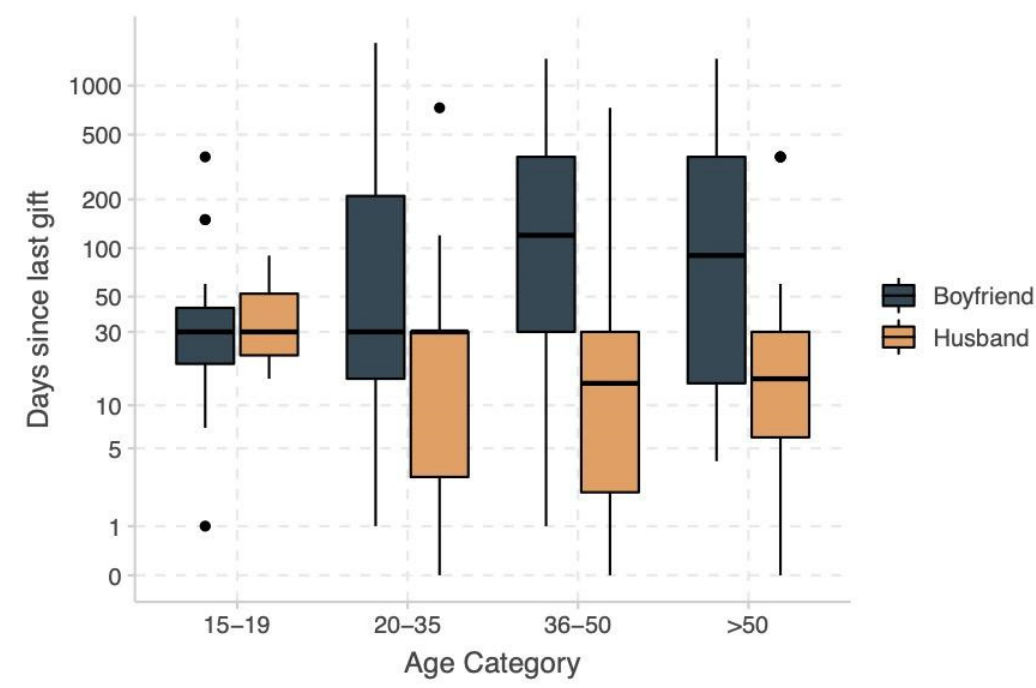

Figure 6. Resource transfer frequency from husbands and boyfriends.

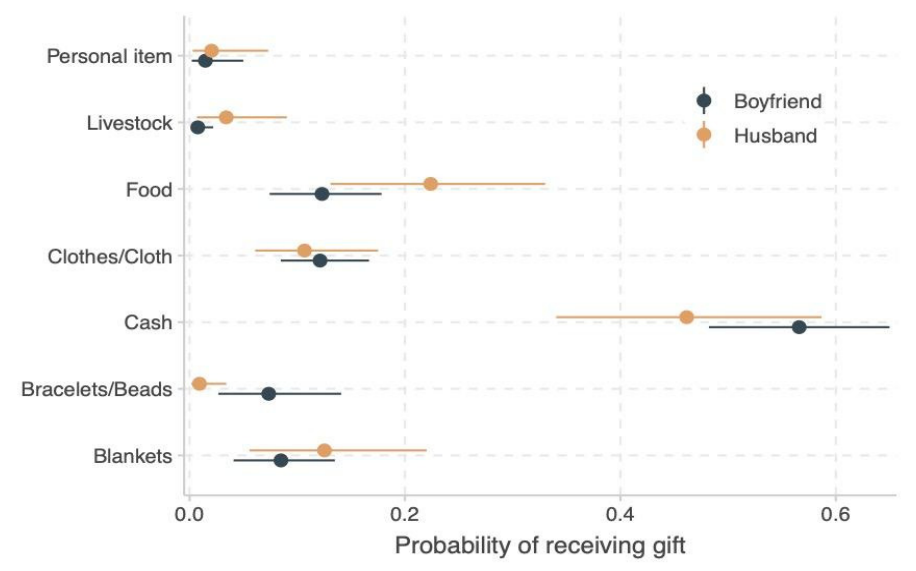

Figure 7. Model predictions in gift type. Model estimates of mean probabilities and $95 \%$ credible intervals shown by horizontal bars.

To better understand the effects of resource transfers on well-being, we evaluated food insecurity and diet breadth as a function of women's partner status (Figure 8). Women were divided into three groups: married with a boyfriend, married without a boyfriend, and unmarried with a boyfriend. Model predictions of mean food insecurity and diet breadth scores indicate that married women with a boyfriend tend to have lower food insecurity than the other two groups, but prediction intervals of all three categories overlap, and the estimate for married women without a boyfriend is highly variable due to a small sample in that category (Table S7). Little difference was found between the three groups for diet breadth (Table S8). 

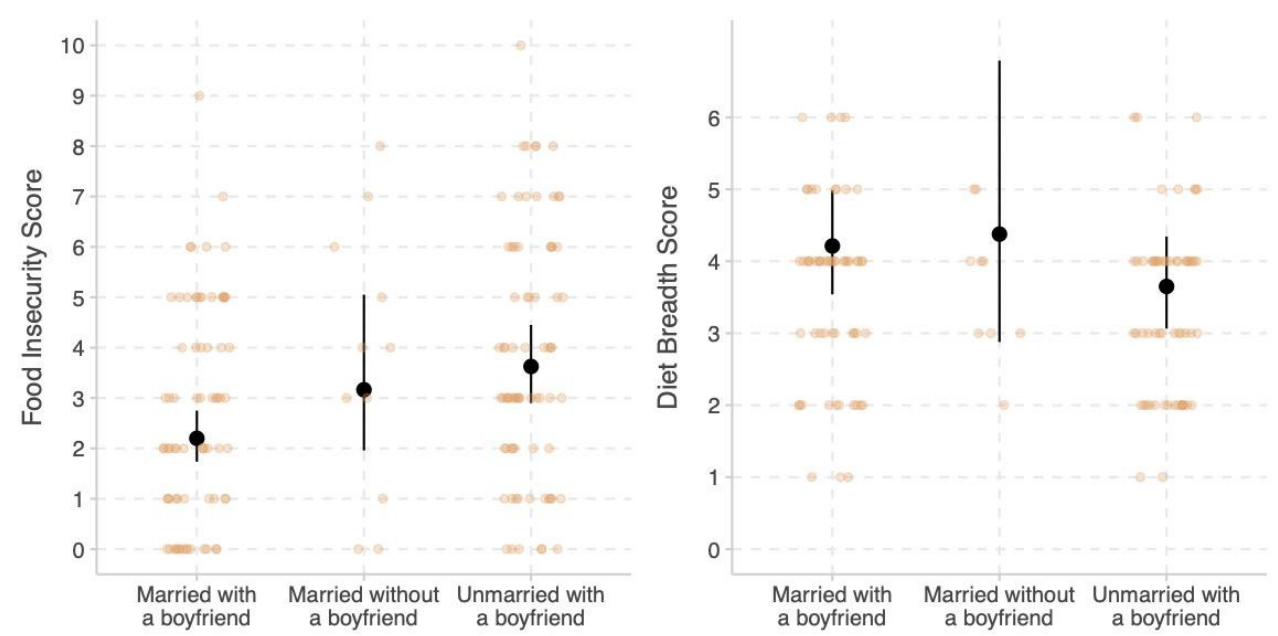

Figure 8. Food insecurity and diet breadth by partner category. Model estimates of category means and $95 \%$ credible intervals shown by vertical bars, plotted alongside raw data.

\section{Discussion}

Here we bring together data on various aspects of Himba lives and livelihoods in order to understand how the particular socioecological context of contemporary Himba life affects their marital and reproductive decision-making. In particular, we are interested in understanding why a normative system of concurrent partnerships and sexual autonomy for women exists in this pastoral system, instead of the more typical pattern of strong mate guarding and restrictions on women's autonomy.

Like many pastoralists, Himba must contend with a stochastic resource base, moving livestock in response to seasonal rainfall patterns and with them, various members of the household. As Bollig describes, these ecological constraints greatly affect household composition:

Himba pastoralism depends on independent movements of livestock camps (ozohambo) and households (ozonganda). After a few weeks of heavy rain (usually January to March) the entire household herd gathers at the main homestead ... . In an average year they stay together for three to four months while the major gardening work is done .... However, a cattle camp ... will be established long before grazing resources become depleted .... . Later, in July or August, male goats and sheep are separated from the household and either a separate small stock camp is established or the small stock herd joins the cattle camp.... At the height of the dry season, between September and December, a number of households shift all their remaining cattle to their cattle camp ... (Bollig 2006, pp. 46-47)

Depending on how many camps are established, and how many able-bodied adults are available for herding, various members of the household might be separated. Our data reflect the general pattern Bollig describes in that husbands and wives are most likely to be separated during the early dry season when the herd is split between the main household and the cattle camp.

Our data also point to a pathway from spousal separation to extra-pair paternity. We show both that spousal separation can lead to long periods of abstinence between spouses, and that sex with boyfriends is common enough to lead to extra-pair paternity. Although more than a quarter of respondents noted that it had been at least a month since they had had sex with their husband, sex with a nonmarital partner was reported to have occurred within the last month in $37 \%$ of cases. Several interlocutors mentioned spousal separation explicitly as the cause of their abstinence, noting that their partner was at the cattle post. Although these separations can be long, they do not necessarily indicate marital strife. As one woman who had been apart from her husband for many months explained, "You know you are divorced if you are in the same place and he doesn't come to you. But if you are just in different places, then you are still together." 
Similarly, interlocutors also remarked that spousal separation is instrumental to maintaining relationships with non-marital partners. Although it is widely seen as normative to have lovers, there is a set of rules that all parties are expected to follow in conducting those relationships. Boyfriends arrive after dark and leave just before dawn, and they often try to determine ahead of time whether their partner is alone. With cell phones becoming increasingly common, this can often be accomplished directly between partners, but as one Himba man explains, others are often enlisted in the process: "I see her when her husband is not around. I can ask around, even kids you can ask, to see if the husband is around. In the evening I would go to a house of someone I know nearby and tell someone to let her know I'm there. Then I go there late at night to see her. We wake up early, before the roosters, and I leave to go back home." For their part, husbands are expected to sleep away from home if they are out after dark (e.g., chasing a rogue cow after sunset). This reduces the chance that a husband and lover will mistakenly encounter each other.

Our aim in this paper was not just to illustrate the correlation between spousal separation and a normalized system of concurrent partnerships, but also to understand why they co-occur. We believe there are three distinct, but interrelated, reasons why spousal separation is associated with sexual autonomy and concurrent partnerships among Himba: (1) Phylogenetic inertia sets the stage for norms promoting female autonomy, while also increasing the costs of mate guarding; (2) demographic and economic factors reduce the costs of lost paternity for men; and (3) the stochastic resource base makes concurrency a viable way for men and women to improve their fitness.

\subsection{Phylogenetic Inertia}

Himba arrived in Namibia via the Bantu expansion, and only became ethnically distinct from their close relatives, the Herero, in the last 100 years (Bollig 2006). Holden and Mace (2003) analyzed shifts in the inheritance structures and modes of production of Bantu groups as they moved across the continent, and depict a general pattern where the adoption of pastoral production led to a shift from matrilineal to patrilineal inheritance. Himba/Herero are unique in that they transfer livestock matrilaterally, and links to one's matriclan are culturally and functionally important (Malan 1995; Gibson 1956). The Bantu language tree that Holden and Mace used to conduct their analysis shows that of the five groups Herero are most closely related to, one practices double descent similar to Herero, and the other four have matrilineal inheritance (Figure S3). Further back, Holden and Mace show that Herero are in the half of the phylogenetic tree with the majority of matrilineal Bantu populations.

Their deep history of matriliny helps to explain why norms promoting female autonomy are likely prominent among Himba. Early ethnographies of Herero describe many of the same sexual practices that exist today, including frequent divorce, high rates of nonmarital sex, acceptance of children born outside of marriage, and senior wives being included in the process of choosing a co-wife (Gibson 1959). Our data compliment these findings, showing that Himba women have relatively high freedom of movement, including lengthy visits unaccompanied by their husbands (Figure 3). These visits serve a dual purpose, keeping up relationships with natal kin, and allowing women opportunities to maintain concurrent relationships. Relatives can also serve as conduits for resource transfers. As one man described, "You cannot give it straight to the woman if she is married. You give 'behind.' You can send it [the gift] to her father or sister, then when she goes there she gets it and she can say it was given to her by her family."

However, the picture of Himba autonomy is complex. Although they have more freedoms than women in many pastoral societies, the limits placed on them indicate that some mate guarding is occurring For example, husbands are most reticent about their wives traveling alone to a funeral or ceremony, which is commonly described by both men and women as being a place where lovers frequently meet. Intimate partner violence is not uncommon, and violence in response to extra-marital sex was second only to child neglect in its acceptability among men and had the highest acceptability rating among women. 
Women and men both linked sexual jealousy to IPV, and several of the women in our interviews mentioned being hit by their partners. One woman explained, "My husband is very jealous. He beats me because he loves me. He doesn't tell me to leave. He just beats me."

There are also complicated notions about non-marital partnerships at play, as evidenced by our vignette study. The majority of men stated that a married woman having a boyfriend is unacceptable, and almost every respondent reported that they knew about this happening. We see similar variation in the types of punishments men reported, ranging from nothing, to mild verbal warnings, to severe physical harm. Several of our respondents described a situation where a husband who found out about his wife's boyfriend snuck into his compound at night (when he knew they would be together) and attacked and killed the boyfriend. We do not know that our interlocutors were all describing the same event or different ones as we did not ask people to give names when they told these stories, but regardless, this exemplifies how dangerous concurrency can be, even in this population where the practice is largely normalized. However, other men described much more measured responses. One reported, "The husband asked the boyfriend not to sleep with his wife. The boyfriend continued anyway. One day the husband met an agemate who told him the man was still sleeping with his wife. That night he didn't come home. Later, he caught the boyfriend again. He called the community and they met and fined the boyfriend 10 cows."

It appears that Himba hold a dual notion of concurrency. On the one hand, they stated that informal partnerships are an integral part of their culture, socially acceptable, and very common. On the other hand, both men and women reported sexual jealousy and there are efforts to constrain spouses' relationships with lovers, especially if they become too frequent and become a threat to the marital union. As one man summed it up, "You don't want other people to sleep with your wife, but it's the tradition." There are several explanations for this tension. Although it may be socially advantageous for men not to buck the current system, individually they may be motivated to maintain as much paternity certainty as possible. Alternatively, as with many double descent systems, Himba may be in a state of disequilibrium, in the process of shifting their social structures from matriliny to patriliny (Scelza et al. 2019). We show here that older men are more likely to be accepting of women's concurrency. Age also had a negative but non-significant effect on men's beliefs about IPV, with older men less likely to believe IPV is acceptable under varying circumstances. These results could represent a generational shift, with more patrilineal, patriarchal norms becoming more prominent. Another possibility is that older men are less incentivized to mate guard because they are further along in their reproductive careers (Pazhoohi et al. 2016).

In addition to the direct impact of matriliny on female autonomy, the particular form of double descent that Himba practice, which involves largely matrilateral inheritance of cattle, impacts the costs and benefits of paternity certainty for men. When wealth can be aggregated and distributed, it can be used to generate fitness-related benefits such as bride-price payments and multiple wives via polygyny. This tends to benefit sons' reproductive success more than daughters', and has been used to explain the correlation between patriliny and pastoral production (Holden and Mace 2003). However, parents must balance the gains that their sons can accrue from inherited wealth with any costs of misallocated investment due to paternity uncertainty.

When cows are inherited matrilaterally, a different calculation becomes relevant. Paternity certainty pertains mainly to relatedness between siblings (as a man is giving to his sister's son). Classic interpretations of the "paternity threshold model" of matrilineal inheritance require levels of paternity uncertainty that are highly unlikely, even in populations such as Himba where extra-pair paternity rates are the highest ever recorded (Greene 1978; but see Rogers 2013 for further discussion). However, when the paternity threshold is considered alongside other socioeconomic factors, stable strategies for this type of matrilineal inheritance can emerge. Fortunato (2012) shows that both polygyny 
and polyandry can make diagonal transfers (from uncle to nephew) beneficial to men's fitness. With their combination of formal polygyny and informal polyandry, and a system of diagonal transfers of wealth, Himba may be a prime example of how high rates of extrapair paternity, via women's concurrency, can be fitness beneficial to men. If this combined system of polygyny and polyandry alongside matrilateral inheritance is beneficial to men, they may be more tolerant of spousal separation and less incentivized to spend time and energy on mate guarding.

\subsection{Demography and Economics}

There are several aspects of Himba sociodemography that affect the costs and benefits of spousal separation and potentially lost paternity. The first is the adult sex ratio. We previously reported that Himba have an ASR of 0.71 (i.e., 71 men for every 100 women, see Scelza et al. 2020c). This was the lowest ASR in that sample of 11 populations, as well as another cross-cultural study of ASR (Schacht et al. 2014). Although the reasons underlying the imbalance in this population are not well understood, a female-biased sex ratio appears to be a long-term trend. Reports from the early 20th century also show a surplus of adult women among Herero, with a sex ratio of 0.75 , based on a sample of 16,201 individuals (Malcolm 1924). Gibson reported similar numbers in the 1959 (Gibson 1959), as did Harpending and Pennington in the 1990s (Harpending and Pennington 1991). The ratio of males to females affects the stability of partnerships. When there are more women than men in a population, men face lower costs to deserting their current partner because there are more alternatives in the population to choose from. In other populations this has led to female-biased sex ratios being associated with less monogamous behavior (Schacht and Mulder 2015; Schacht and Kramer 2016).

Another factor that must be considered is the value of child labor. When children contribute to household production, they offset some of their own costs, mitigating potential losses to men if they care for children who are not their biological offspring. Although we do not present data on child labor here, our previous findings lend support to this idea. Himba men have been shown to bias their investments in biological versus non-biological children, in what appears to be a functional response to their productive value (Prall and Scelza 2020b). Girls, who Himba resoundingly praise as being valuable laborers, have poorer anthropometric outcomes when they are believed to be omoka (non-biological offspring). Our data support the idea that this may be because girls have to work harder to "earn their keep" in this situation. One Himba woman said to us, "Sometimes when the child starts to grow up, the child will be working very hard and the husband might start to like that child, even more than his own child." On the other hand, Himba boys, whose labor is generally considered to be less valuable, are more likely to be fostered out when they are believed to be omoka. One woman explained, "When the husband talks about that child, he hates him. When he sees him he tells you to take that child to your parents." In this case, it seems that men may be lowering their own investment costs when paternity certainty is low and the net cost of the child is greater.

\subsection{Benefits of Concurrency}

Our data show that women can benefit directly from having multiple partners. Women with both husbands and boyfriends have greater food security than those who have partners of only a single type. Although it is difficult to identify a causal pathway from concurrency to greater food security, the mix of data we present serves to illuminate how husbands and lovers support women in different ways. Husbands tend to be more reliable partners, giving gifts more often and in greater quantities than boyfriends. Boyfriends are less likely to provide food or livestock than husbands, but more likely to give cash. Women have noted that this is useful because cash can be given discreetly, and can be used for a wide variety of purposes, including for food, medical care, or transportation. These data show that the bond between spouses is strong-women rely on their husbands as their primary sources of support, and husbands largely fulfill that role. Boyfriends, on the other 
hand, are less socially obligated to give, and so there is more variability in the frequency of their giving, and in fact, whether he gives her anything of note at all.

Our qualitative data reveal an important aspect of resource transfer patterns that did not show up in our quantitative data. Multiple women reported that boyfriends are called upon in critical times, either when there is an inordinately large expense, or when their husband is not available to help. One woman explained, "They [her friends] could tell him [her boyfriend] that I needed something, so he would know ... . If he saw I was having a problem he would give something to me to help, because we have been together so long ... . My child was sick and my friend went to tell [the boyfriend] and he came to me and gave me $\mathrm{N} \$ 1000 . "$ These rare events are unlikely to show up in the recall data described above, which is better suited for describing general transfer patterns. In addition, the safety net of knowing that you could ask if you needed something is also an important aspect of resource security, and one that would not be picked up in our quantitative data. As one woman stated, "He's never given me anything but I love him. I know if I asked he would give me something."

Boyfriends, therefore, help in ways that can be either complementary or supplementary. This may be particularly critical when spousal separation is common because there are long periods of time (particularly historically when cars and cell phones were less common) when husbands may be unable to help. If a child is sick, or an unexpected food shortage arises, boyfriends can step in. One woman stated, "If you are tired of asking the husband, you can ask the boyfriend. It's good to have both to ask," while another said, "You need to eat two times. From the husband and the boyfriend."

It should be noted that where this trickles down to affect the well-being of a couple's children, both the husband's and the wife's fitness can be positively affected by concurrency. This creates a system of generalized reciprocity for men. Husbands invest in their wives' children, only some of which are his biological offspring - which comes at a cost. However, help comes in toward those children from his wives' informal partners. In addition, a man may be providing some investment toward children he has with his lovers, but the majority of investment in those children comes from their social father. Formal modeling and more specific empirical data would be needed to know whether this results in a net benefit for most men, but our data point toward this being a stable response in a system with a stochastic resource base and high mate guarding costs. Men can accrue the kinds of standard gains to fitness that are predicted through sexual selection theory, and any paternity loss that occurs in their marriage is buffered by support from other men.

\section{Conclusions}

Spousal separation is a recurrent cultural phenomenon in marriages around the world, often driven by ecological constraints that require men and women to carry on their productive activities separately. In many situations, this leads men to place a myriad of constraints on women's freedoms in order to ensure paternity certainty during his absence. However, restricting women's movements and behavior is costly, so costly in some instances that it may not be worthwhile. To date, we lack a clear understanding about why one outcome or the other emerges. Here, in this case study of Himba pastoralists, we propose that rather than there being a single explanatory variable, a confluence of historical, demographic, social, and economic circumstances must be studied together in order to understand why one strategy becomes dominant over the other in a particular setting.

Among Himba, a long history of matriliny opened the door to retaining (at least for the time being) social norms that promote female autonomy and sexual freedom for both men and women, even after the introduction of pastoralism. The drought-prone ecology of northwest Namibia, combined with a need to break up livestock across multiple camps, makes mate guarding particularly difficult, which may have further disincentivized shifting from matrilineal to patrilineal inheritance. Instead, a reciprocal system of caretaking, through both formal and informal partnerships, gives both women and men greater ability to cope in this environment. The system is further bolstered by a productive system that is 
highly reliant on child labor and a female-biased ASR, which allows men to make up for marital paternity loss through their own extra-marital partnerships more easily.

One of the values of a mixed-method study such as this is that it pieces together various population-specific elements into an explanatory framework. However, in being so specific, one might question how broadly applicable the Himba case is to other populations that practice spousal separation. We find that this particularist view, in conjunction with the theoretical grounding of human behavioral ecology, illuminates a set of strategies that are relevant well beyond the confines of northwest Namibia. We show how key components of reproductive decision-making (e.g., the cost of mate guarding, the ameliorating effect of child labor, the ASR) combine to form a stable strategy. Each of these components has been described before as being influential on human mating and marriage behavior. However, in trying to understand the "messiness of the human phenome" (Gurven 2020), we need to spend more time looking at their intersections.

Supplementary Materials: The following are available online at https:/ /www.mdpi.com/article/10 .3390/socsci10050174/s1, Figure S1: Inheritance structure and mode of production for Himba and related groups, Table S1: Intimate partner violence model results, Table S2: Boyfriend vignette model results, Table S3: Days since last gift model results, Table S4: Gift type model results, Table S5: Food insecurity model results, Table S6: Diet breadth model results.

Author Contributions: Conceptualization, B.S.; methodology, B.S., S.P. and K.S.; data collection, B.S., S.P. and K.S.; formal analysis, S.P.; writing—original draft preparation, B.S.; writing—review and editing, S.P. and K.S.; visualization, S.P.; funding acquisition, B.S. All authors have read and agreed to the published version of the manuscript.

Funding: This research was funded by the National Science Foundation, grant number BCS-1534682. Additional funding was provided by the Max Planck Institute for Evolutionary Anthropology.

Data Availability Statement: Because of the sensitive nature of these data, they may be available upon request from the authors, but are not currently available on a public server.

Acknowledgments: First and foremost, we thank the community of Omuhonga, whose families have opened up their hearts and homes to us and shared their life stories for the last 10 years. John Jakurama, Cancy Louis, Gita Louis, and Calvin Kenaumue provided vital translation and research assistance in the field. Jacob Sheehama also provided support in Namibia. We also thank Richard McElreath, Renee Hagen, and Kim Hill for fruitful conversations about the topics in this manuscript.

Conflicts of Interest: The authors declare no conflict of interest. The funders had no role in the design of the study; in the collection, analyses, or interpretation of data; in the writing of the manuscript, or in the decision to publish the results.

\section{References}

Barry, Herbert. 2007. Customs Associated with Premarital Sexual Freedom in 143 Societies. Cross-Cultural Research 41: 261-72. [CrossRef]

Becker, Anke. 2019. On the Economic Origins of Restrictions on Women's Sexuality. CESifo Working Paper No. 7770. Available online: https://ssrn.com/abstract=3432818 (accessed on 7 January 2021).

Becker, Gary S. 1985. Human Capital, Effort, and the Sexual Division of Labor. Journal of Labor Economics 3 Pt 2: S33-S58. [CrossRef]

Beckerman, Stephen, and Paul Valentine. 2002. Cultures of Multiple Fathers: The Theory and Practice of Partible Paternity in Lowland South America. Gainesville: University Press of Florida.

Betzig, Laura. 1989. Causes of Conjugal Dissolution: A Cross-Cultural Study. Current Anthropology 30: 654-76. [CrossRef]

Bollig, Michael. 2006. Risk Management in A Hazardous Environment: A Comparative Study of Two Pastoral Societies. Studies in Human Ecology and Adaption. Available online: https://www.springer.com/gp/book/9780387275819 (accessed on 7 January 2021).

Borgerhoff Mulder, Monique, and Cody T. Ross. 2019. Unpacking Mating Success and Testing Bateman's Principles in a Human Population. Proceedings of the Royal Society B 286: 20191516. [CrossRef] [PubMed]

Bürkner, Paul-Christian. 2017. Brms: An R Package for Bayesian Multilevel Models Using Stan. Journal of Statistical Software 80: 1-28. [CrossRef]

Buss, David M. 2002. Human Mate Guarding. Neuroendocrinology Letters 23: 23-29. [PubMed]

Cronk, Lee. 1991. Human Behavioral Ecology. Annual Review of Anthropology 20: 25-53. [CrossRef]

Daly, Martin, Margo Wilson, and Suzanne J. Weghorst. 1982. Male Sexual Jealousy. Ethology and Sociobiology 3: 11-27. [CrossRef] 
Deitchler, Megan, Terri Ballard, Anne Swindale, and Jennifer Coates. 2010. Validation of a Measure of Household Hunger for Cross-Cultural Use. Washington, DC: Food and Nurtrition Technical Assistance II Project (FANTA-2), Acedemy for Educational Development.

Dickemann, Mildred. 1979. The Ecology of Mating Systems in Hypergynous Dowry Societies. Social Science Information 18: 163-95. [CrossRef]

Durkheim, Emile. 1933. The Division of Labor in Society. Translated by George Simpson. New York: The Macmillan Company.

Dyson-Hudson, Rada, and Neville Dyson-Hudson. 1980. Nomadic Pastoralism. Annual Review of Anthropology 9: 15-61. [CrossRef]

Evans-Pritchard, Edward Evan. 1951. Kinship and Marriage among the Nuer. Oxford: Clarendon Press.

Fortunato, Laura. 2012. The Evolution of Matrilineal Kinship Organization. Proceedings of the Royal Society B: Biological Sciences 279: 4939-945. [CrossRef] [PubMed]

Gibson, Gordon D. 1956. Double Descent and Its Correlates among the Herero of Ngamiland. American Anthropologist 58: 109-39. [CrossRef]

Gibson, Gordon D. 1959. Herero Marriage. Rhodes-Livingston Journal 24: 1-37.

Goetz, Aaron T., Todd K. Shackelford, Valerie G. Starratt, and William F. McKibbin. 2008. Intimate Partner Violence. In Evolutionary Forensic Psychology: Darwinian Foundations of Crime and Law. Edited by Joshua D. Duntley and Todd K. Shackelford. Oxford: Oxford University Press. [CrossRef]

Gough, Kathleen. 1971. Nuer Kinship. The Translation of Culture: Essays to EE Evans-Pritchard 117: 79.

Greene, Penelope J. 1978. Promiscuity, Paternity, and Culture. American Ethnologist 5: 151-59. [CrossRef]

Guemple, Lee. 1986. Men and Women, Husbands and Wives: The Role of Gender in Traditional Inuit Society. Études/Inuit/Studies 10: 9-24.

Gurven, Michael D. 2020. Greater Humility Can Help Expand Evolutionary Social Science. Evolution and Human Behavior 41: 456-57. [CrossRef]

Gurven, Michael, Jeffrey Winking, Hillard Kaplan, Christopher von Rueden, and Lisa McAllister. 2009. A Bioeconomic Approach to Marriage and the Sexual Division of Labor. Human Nature 20: 151-83. [CrossRef] [PubMed]

Guttentag, Marcia, and Paul F. Secord. 1983. Too Many Women? The Sex Ratio Question. New York: SAGE Publications, Incorporated.

Harpending, Henry, and Renee Pennington. 1991. Age Structure and Sex-Biased Mortality among Herero Pastoralists. Human Biology 63: 329-53.

Hazel, Mary-Ashley. 2012. Sexually Transmitted Diseases Among Pastoralists in Kaokoland, Namibia: Epidemiology, Ecology and Behavior. Ph.D. dissertation, University of Michigan, Ann Arbor, MI, USA. Available online: https://deepblue.lib.umich.edu/ bitstream/handle/2027.42/96083/ahazel_1.pdf?sequence=1 (accessed on 7 January 2021).

Hendrix, Lewellyn, and Willie Pearson. 1995. Spousal Interdependence, Female Power and Divorce: A Cross-Cultural Examination. Journal of Comparative Family Studies 26: 217-32.

Hill, Kim Ronald, and A. Magdalena Hurtado. 1996. Ache Life History: The Ecology and Demography of a Foraging People. New York: Transaction Publishers.

Holden, Clare Janaki, and Ruth Mace. 2003. Spread of Cattle Led to the Loss of Matrilineal Descent in Africa: A Coevolutionary Analysis. Proceedings of the Royal Society of London B: Biological Sciences 27: 2425-33. [CrossRef] [PubMed]

Hrdy, Sarah Blaffer. 2000. The Optimal Number of Fathers: Evolution, Demography, and History in the Shaping of Female Mate Preferences. Annals of the New York Academy of Sciences 907: 75-96. [CrossRef]

Jokela, Markus, Anna Rotkirch, Ian J. Rickard, Jenni Pettay, and Virpi Lummaa. 2010. Serial Monogamy Increases Reproductive Success in Men but Not in Women. Behavioral Ecology 21: 906-12. [CrossRef]

Knowles, Joan Nancie. 1993. Power, Influence and the Political Process among Iloitai Maasai. Ph.D. thesis, Durham University, Durham, UK.

Llewellyn-Davies, Melissa. 1978. Two Contexts of Solidarity among Pastoral Maasai Women. In Women United, Women Divided: Cross-Cultural Perspectives on Female Solidarity. Bloomington: Indiana University Press.

Mackie, Gerry. 1996. Ending Footbinding and Infibulation: A Convention Account. American Sociological Review 61: 999-1017. [CrossRef]

Malan, Johan S. 1995. Peoples of Namibia. Wingate Park: Rhino Publishers.

Malcolm, L. W. G. 1924. Sex-Ratio in African Peoples. American Anthropologist 26: 454-73. [CrossRef]

Murdock, George P., and Caterina Provost. 1973. Factors in the Division of Labor by Sex: A Cross-Cultural Analysis. Ethnology 12: 203-25. [CrossRef]

Mwangi, Esther, and Elinor Ostrom. 2009. A Century of Institutions and Ecology in East Africa's Rangelands: Linking Institutional Robustness with the Ecological Resilience of Kenya's Maasailand. In Institutions and Sustainability. Berlin and Heidelberg: Springer, pp. 195-222.

Pazhoohi, Farid, Martin Lang, Dimitris Xygalatas, and Karl Grammer. 2016. Religious Veiling as a Mate-Guarding Strategy: Effects of Environmental Pressures on Cultural Practices. Evolutionary Psychological Science 3: 118-24. [CrossRef]

Prall, Sean P., and Brooke A. Scelza. 2020a. Resource Demands Reduce Partner Discrimination in Himba Women. Evolutionary Human Sciences 2: e45. [CrossRef] 
Prall, Sean P., and Brooke A. Scelza. 2020b. Why Men Invest in Non-Biological Offspring: Paternal Care and Paternity Confidence among Himba Pastoralists. Proceedings of the Royal Society B 287: 20192890. [CrossRef]

Prall, Sean P., Gandhi Yetish, Brooke A. Scelza, and Jerome M. Siegel. 2018. The Influence of Age-and Sex-Specific Labor Demands on Sleep in Namibian Agropastoralists. Sleep Health 4: 500-8. [CrossRef] [PubMed]

Randall, Sara. 1995. Low Fertility in a Pastoral Population: Constraints or Choice? In Human Reproductive Decisions. Berlin and Heidelberg: Springer, pp. 279-96.

Rogers, Alan R. 2013. Genetic Relatedness to Sisters' Children Has Been Underestimated. Proceedings of the Royal Society B: Biological Sciences 280. Available online: http://rspb.royalsocietypublishing.org/content/280/1751/20121937.short (accessed on 12 January 2021). [CrossRef] [PubMed]

Scelza, Brooke A. 2011a. Female Choice and Extra-Pair Paternity in a Traditional Human Population. Biology Letters 7: 889-91. [CrossRef] [PubMed]

Scelza, Brooke A. 2011b. Female Mobility and Postmarital Kin Access in a Patrilocal Society. Human Nature 22: 377-93. [CrossRef] [PubMed]

Scelza, Brooke A. 2013. Choosy But Not Chaste: Multiple Mating in Human Females. Evolutionary Anthropology: Issues News, and Reviews 22: 259-69. [CrossRef] [PubMed]

Scelza, Brooke A., and Joan B. Silk. 2014. Fosterage as a System of Dispersed Cooperative Breeding. Human Nature 25: 448-64. [CrossRef]

Scelza, Brooke A., and Sean P. Prall. 2018. Partner Preferences in the Context of Concurrency: What Himba Want in Formal and Informal Partners. Evolution and Human Behavior 39: 212-19. [CrossRef]

Scelza, Brooke A., Sean P. Prall, and Kathrine Starkweather. 2020a. Paternity Confidence and Social Obligations Explain Men's Allocations to Romantic Partners in an Experimental Giving Game. Evolution and Human Behavior 41: 96-103. [CrossRef]

Scelza, Brooke A., Sean P. Prall, and Nancy E. Levine. 2019. The Disequilibrium of Double Descent: Changing Inheritance Norms among Himba Pastoralists. Philosophical Transactions of the Royal Society B: Biological Sciences 374: 20180072. [CrossRef] [PubMed]

Scelza, Brooke A., Sean P. Prall, Natalie Swinford, Shyamalika Gopalan, Elizabeth G. Atkinson, Richard McElreath, Jacob Sheehama, and Brenna M. Henn. 2020b. High Rate of Extrapair Paternity in a Human Population Demonstrates Diversity in Human Reproductive Strategies. Science Advances 6: eaay6195. [CrossRef] [PubMed]

Scelza, Brooke A., Sean P. Prall, Tami Blumenfield, Alyssa N. Crittenden, Michael Gurven, Michelle Kline, Jeremy Koster, Geoff Kushnick, Siobhán M. Mattison, and Elizabeth Pillsworth. 2020c. Patterns of Paternal Investment Predict Cross-Cultural Variation in Jealous Response. Nature Human Behaviour 4: 20-26. [CrossRef]

Schacht, Ryan, and Karen L. Kramer. 2016. Patterns of Family Formation in Response to Sex Ratio Variation. PLoS ONE 11: e0160320. [CrossRef] [PubMed]

Schacht, Ryan, and Monique Borgerhoff Mulder. 2015. Sex Ratio Effects on Reproductive Strategies in Humans. Royal Society Open Science 2: 140402. [CrossRef] [PubMed]

Schacht, Ryan, Karen L. Kramer, Tamás Székely, and Peter M. Kappeler. 2017. Adult Sex Ratios and Reproductive Strategies: A Critical Re-Examination of Sex Differences in Human and Animal Societies. Philosophical Transactions of the Royal Society 372. [CrossRef] [PubMed]

Schacht, Ryan, Kristin Liv Rauch, and Monique Borgerhoff Mulder. 2014. Too Many Men: The Violence Problem? Trends in Ecology E Evolution 29: 214-22. [CrossRef]

Sedziafa, Alice Pearl, and Eric Y. Tenkorang. 2016. Kin Group Affiliation and Marital Violence Against Women in Ghana. Violence and Victims 31: 486-509. [CrossRef] [PubMed]

Smuts, Barbara. 1995. The Evolutionary Origins of Patriarchy. Human Nature 6: 1-32. [CrossRef] [PubMed]

Stan Development Team. 2019. RStan: The R Interface to Stan. Available online: https://cran.r-project.org/web/packages/rstan/ vignettes/rstan.html (accessed on 12 January 2021).

Starkweather, Katherine E., and Raymond Hames. 2012. A Survey of Non-Classical Polyandry. Human Nature 23: 149-72. [CrossRef] [PubMed]

Stieglitz, Jonathan, Benjamin C. Trumble, Hillard Kaplan, and Michael Gurven. 2018. Marital Violence and Fertility in a Relatively Egalitarian High-Fertility Population. Nature Human Behaviour 2: 565-72. [CrossRef] [PubMed]

Strassmann, Beverly I. 1992. The Function of Menstrual Taboos among the Dogon. Human Nature 3: 89-131. [CrossRef]

Svedberg, Peter. 1990. Undernutrition in Sub-Saharan Africa: Is There a Gender Bias? The Journal of Development Studies 26: 469-86. [CrossRef]

Takyi, Baffour K., and Stephen Obeng Gyimah. 2007. Matrilineal Family Ties and Marital Dissolution in Ghana. Journal of Family Issues 28: 682-705. [CrossRef]

Talle, Aud. 1994. The Making of Female Fertility: Anthropological Perspectives on a Bodily Issue. Acta Obstetricia et Gynecologica Scandinavica 73: 280-83. [CrossRef] [PubMed]

Von Rueden, Christopher, Michael Gurven, and Hillard Kaplan. 2011. Why Do Men Seek Status? Fitness Payoffs to Dominance and Prestige. Proceedings of the Royal Society B: Biological Sciences 278: 2223-32. [CrossRef] [PubMed] 
Walker, Robert S., Mark V. Flinn, and Kim R. Hill. 2010. Evolutionary History of Partible Paternity in Lowland South America. Proceedings of the National Academy of Sciences 107: 19195-200. [CrossRef] [PubMed]

Wamani, Henry, Anne N. Åstrøm, Stefan Peterson, James K. Tumwine, and Thorkild Tylleskär. 2007. Boys Are More Stunted than Girls in Sub-Saharan Africa: A Meta-Analysis of 16 Demographic and Health Surveys. BMC Pediatrics 7: 17. [CrossRef] [PubMed]

Wilson, Margo, and Martin Daly. 1995. The Man Who Mistook His Wife for a Chattel. In The Adapted Mind: Evolutionary Psychology and the Generation of Culture. New York: Oxford University Press. 